\title{
Jam3 promotes migration and suppresses apoptosis of renal carcinoma cell lines
}

\author{
XUDONG LI $^{1 *}$, AIPING YIN $^{1 *}$, WENJING ZHANG $^{1}$, FEI ZHAO $^{2}$, JIA LV $^{1}$, JING LV $^{1}$ and JIPING SUN ${ }^{1}$ \\ Departments of ${ }^{1}$ Nephrology and Urinary Surgery, and ${ }^{2}$ Gynaecology and Obstetrics, \\ The First Affiliated Hospital of Medical College, Xi'an Jiaotong University, Xi'an, Shaanxi 710061, P.R. China
}

Received July 25, 2017; Accepted August 6, 2018

DOI: $10.3892 / \mathrm{ijmm} .2018 .3854$

\begin{abstract}
As a common type of renal cancer, renal cell carcinoma ( $\mathrm{RCC}$ ) has a high annual mortality rate. The incidence of RCC has been increasing in China and worldwide. A large number cases of RCC are diagnosed at late stages, often with local and/or systematic metastasis. Surgical resection of RCC is only suitable for a small number of patients with early stage tumors, and thus, novel therapeutic methods are required. Junctional adhesion molecule 3 (Jam3) is a member of the junctional adhesion molecule family, which has been linked to epithelial and cancer cell proliferation. The present study investigated whether the Jam 3 gene affected RCC growth via proliferation and apoptosis. The expression and biological function of Jam 3 in renal carcinoma cells was investigated. The mRNA and protein levels of Jam3 were examined by reverse transcription-polymerase chain reaction and western blot analyses. The role of Jam 3 in the migration and apoptosis of renal carcinoma cells was determined using small interfering RNA, wound-healing assays, flow cytometry, and cell migration assays. In the cell migration assays, E-cadherin, $\mathrm{N}$-cadherin, integrin $\beta 1$, and matrix metalloproteinase (MMP)-2 proteins were detected by western blot analysis. It was shown that the expression of Jam3 was significantly elevated in human renal carcinoma cells compared with that in renal tubular epithelial cells. The knockdown of Jam3 inhibited renal carcinoma cell migration and promoted renal carcinoma cell apoptosis. It also increased the protein levels of E-cadherin and reduced the protein levels of $\mathrm{N}$-cadherin, integrin $\beta 1$ and MMP-2. The inhibition of Jam 3 promoted migration and suppressed apoptosis of renal carcinoma cells via regulation of the expression of E-cadherin, $\mathrm{N}$-cadherin, integrin $\beta 1$ and MMP-2. Therefore,
\end{abstract}

Correspondence to: Dr Jiping Sun, Department of Nephrology and Urinary Surgery, The First Affiliated Hospital of Medical College, Xi'an Jiaotong University, 277 West Yanta Road, Xi'an, Shaanxi 710061, P.R. China

E-mail: sjp6325@yeah.net

${ }^{*}$ Contributed equally

Key words: Jam3, renal carcinoma, migration, apoptosis
Jam3 was suggested as a novel target gene for the diagnosis and treatment of RCC.

\section{Introduction}

Renal cell carcinoma (RCC) is a metastatic, heterogeneous disease that is resistant to conventional treatment modalities $(1,2)$. Resistance to therapy continues to be a major challenge to the effective treatment of patients with metastatic RCC $(2,3)$. It is estimated that $25 \%$ of patients have advanced stage RCC, which includes locally invasive or metastatic RCC. In addition, it was reported that one-third of patients who underwent partial lesion resection experienced recurrence (4). The median survival rate of patients with metastatic cancer is $\sim 13$ months (5). Therefore, a more effective treatment for RCC is urgently required. In previous years, gene-targeted therapy has become promising for the treatment of RCC. Over the last decade, the treatment of RCC has evolved to include drugs that target the vascular endothelial growth factor (VEGF) and mammalian target of rapamycin (mTOR) pathways, resulting in substantially improved outcomes for the patient population (6). However, despite prolonged survival rates, the majority of patients develop resistance to VEGF- and mTOR-targeted therapies. It is important to identify novel anticancer agents to combat this life-threatening disease (6).

Junctional adhesion molecule 3 (Jam3) is a vascular adhesion molecule, which regulates adhesion and interactions among or between cells and the extracellular matrix (5). It has been reported that Jam 3 enhances the expression and activation of adhesion molecules in vascular endothelial cells $(7,8)$. The methylation status of Jam3 is a biomarker for the diagnosis of preneoplastic and neoplastic lesions of the cervix and promotes cervical cancer progression (9). Therefore, the present study examined whether Jam3 enhanced and influenced migration and apoptosis in RCC. E-cadherins are calcium-dependent cell adhesion proteins, and their enhancement can reduce cancer migration (10). Integrins are cell adhesion receptors, which are important in the interactions between cells and the extracellular matrix, and in cell-cell interactions. Integrin $\beta 1$ has also been shown to contribute to cancer migration (11). Matrix metalloproteinase (MMP)-2 is known as an interstitial collagenase and fibroblast collagenase encoded by the MMP-2 gene in humans. Tumor cells promote migration by degrading collagen through the secretion of MMP-2. MMP-2 may alter 
tumor viability and invasion by regulating lymphangiogenesis in addition to angiogenesis (12).

However, no study published to date has examined the role of Jam 3 in renal carcinoma cells. The present study investigated whether the expression of Jam 3 is increased in renal carcinoma cells and determined the important migration protein of RCC in this process. The results may provide information to assist in the development of novel therapeutic targets and strategies for the treatment of RCC.

\section{Materials and methods}

Cell culture. The HK-2 cell line (adenovirus 50-immortalized line of human renal tubular epithelial cells), Caki-1 and 786-0 cell lines (Simian virus 26-immortalized line of human ACHN) were obtained from American Type Culture Collection (Manassas, VA, USA) and cultured in Dulbecco's modified Eagle's medium (DMEM) with 10\% fetal bovine serum (FBS; Gibco; Thermo Fisher Scientific, Inc., Waltham, MA, USA). The cells were cultured at $37^{\circ} \mathrm{C}$ in a $5 \% \mathrm{CO}_{2}$ atmosphere, and growth status was measured using an inverted microscope. On reaching 80-90\% confluence, the cells were subcultured and digested with trypsin. The cell activities were examined by a routine MTT assay. The detailed protocol has been described previously (13-16).

Western blot analysis. The HK-2, Caki-1 and 786-0 cells were homogenized with M2 buffer containing $20 \mathrm{mM}$ Tris- $\mathrm{HCl}$ (pH 7.6), 0.5\% NP-40, $250 \mathrm{mM} \mathrm{NaCl}, 3$ mM EDTA, $2 \mathrm{mM}$ DTT, $0.5 \mathrm{mM}$ phenylmethylsulfonylfluoride, $20 \mathrm{mM}$ $\beta$-glycerophosphate, $1 \mathrm{mM}$ sodium vanadate, and $1 \mu \mathrm{g} / \mathrm{ml}$ leupeptin. Protein concentrations were determined using the BCA assay (Bioteke Corporation, Beijing, China). Equal quantities $(40 \mu \mathrm{g})$ of protein homogenates were analyzed using $12 \%$ sodium dodecyl sulfate polyacrylamide gel electrophoresis and transferred onto a polyvinylidene fluoride membrane (EMD Millipore, Billerica, MA, USA), which was then blocked with Tris-buffered saline (TBS) and 0.1\% Tween-20 (TBS-T) containing $5 \%$ bovine serum albumin (Sangon Biotech Co., Ltd., Shanghai, China) for $2 \mathrm{~h}$ at $37^{\circ} \mathrm{C}$. The membrane was subsequently washed three times with TBS-T. The membranes were probed with primary antibody overnight at $4^{\circ} \mathrm{C}$ followed by incubation with secondary antibody for $1 \mathrm{~h}$ at room temperature. The signals were detected via enhanced chemiluminescence (GE Healthcare Life Sciences, Little Chalfont, UK) according to the manufacturer's protocol. The band density was quantified using ImageJ software 5.0 (National Institutes of Health, Bethesda, MD, USA) and normalized relative to glyceraldehyde 3-phosphate dehydrogenase (GAPDH). The primary antibodies used were as follows: Monoclonal anti-Jam3 (WH0083700M1; 1:2,000 dilution; human; Sigma-Aldrich; Merck KGaA, Darmstadt, Germany), E-cadherin (5296; 1:1,000 dilution; human; Cell Signaling Technology, Inc., Danvers, MA, USA), N-cadherin (14215; 1:1,000 dilution; human; Cell Signaling Technology, Inc.), integrin $\beta 1$ (ab24693; 1:2,000 dilution; human; Abcam, Cambridge, UK), MMP-2 (ab86607; 1:2,000 dilution; human; Abcam), B cell lymphoma 2 (Bcl-2; ab692; 1:2,000 dilution; human; Abcam) Bcl-2-associated X protein (Bax; ab77566; 1:2,000 dilution; human; Abcam), and GAPDH (sc293335; 1:2,000 dilution; human; Santa Cruz Biotechnology,
Inc., Santa Cruz, CA, USA). A horseradish peroxidase-labeled secondary antibody (7076; 1:1,000 dilution; human; Cell Signaling Technology, Inc.) was used as the secondary antibody.

Reverse transcription-quantitative polymerase chain reaction (RT-qPCR) analysis. The HK-2, Caki-1 and 786-0 cells were cultured in six-well plates for $24 \mathrm{~h}$. RNA was obtained from these cells using lysis buffer (Bioteke Corporation) and reversed transcribed using a Prime ScriptRT reagent kit (Takara Bio, Inc., Shiga, Japan) according to the manufacturer's protocol. The mRNA expression level of Jam3 was determined via $\mathrm{qPCR}$ analysis. The reaction was processed using Real Master mix (SYBR-Green; Tiangen Biotech Co., Ltd., Beijing, China) in a total volume of $10 \mu \mathrm{l}$ containing $2 \mu \mathrm{l}$ cDNA, $5 \mu \mathrm{l} \mathrm{SYBR}$ solution, $0.15 \mu \mathrm{l}$ each of forward and reverse primers, and up to $2.7 \mu 1 \mathrm{dd}_{2} \mathrm{O}$. The primer sequences for Jam3 were as follows: Forward 5'-CGTAGTTAGGGT TGGGATTC-3' and reverse 5'-GAAATCCGACGACTATCC GA-3'; and the primer sequences for $\beta$-actin were as follows: Forward 5'-GTGGACATCCGCAAAGAC-3' and reverse 5'-GAAAGGGTGTAACGCAACT-3'. The PCR amplification was performed as follows: $95^{\circ} \mathrm{C}$ for $10 \mathrm{~min}$, followed by 40 cycles at $95^{\circ} \mathrm{C}$ for $15 \mathrm{sec}$, and $58-60^{\circ} \mathrm{C}$ for $1 \mathrm{~min}$, in a total volume of $10 \mu \mathrm{l}$ based on the $7900 \mathrm{HT}$ Fast Real-Time PCR system (Applied Biosystems; Thermo Fisher Scientific, Inc.). The expression of Jam3 was analyzed using the $2^{-\Delta \Delta C q}$ method (17).

Cell transfection. The Caki-1 and 786-0 cells were cultured in serum-free DMEM without antibiotics. Jam3 small interfering (si)RNA (sc-43872) and negative siRNAs (sc-37007) were obtained from Santa Cruz Biotechnology, Inc. The cells were transfected using Lipofectamine 2000 (Invitrogen; Thermo Fisher Scientific, Inc.) according to the manufacturer's protocol. Following $6 \mathrm{~h}$ of transfection, fresh medium was added to the transfected cells and cultured for up to $24 \mathrm{~h}$. The cells were collected to verify gene silencing by assessing the protein expression of Jam3 using western blot analysis.

Flow cytometry. Following transfection with or without Jam3 siRNA for $6 \mathrm{~h}$, fresh medium was added to the transfected cells and cultured for up to $24 \mathrm{~h}$, Subsequently, Annexin V/propidium iodide staining was detected by flow cytometry using the APC Annexin V kit (BD Biosciences, Franklin Lakes, NJ, USA) according to the manufacturer's protocol. The flow cytometric analysis was performed using SLR II flow cytometer software. Data were analyzed using FACSDIVA software 6.0 (BD Biosciences).

Wound-healing assay. The Caki-1 and 786-0 cells were seeded in six-well plates at a density of $2 \times 10^{5}$ cells per well. The cells were then transfected with negative or Jam 3 siRNA for $24 \mathrm{~h}$ and grown to 80-90\% confluence. The cell layers were scratched with a $20-\mu 1$ pipette tip, washed three times with phosphate-buffered saline and cultured in medium without FBS. Images of the wound area were captured using a fluorescence microscope every $24 \mathrm{~h}$. The cells on either side of the wound migrated into the cell-free area. The widths of three different wound surfaces of each group were recorded and measured using ImageJ software. The experiment was repeated at least three times. 
A

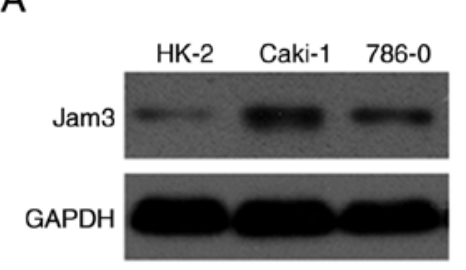

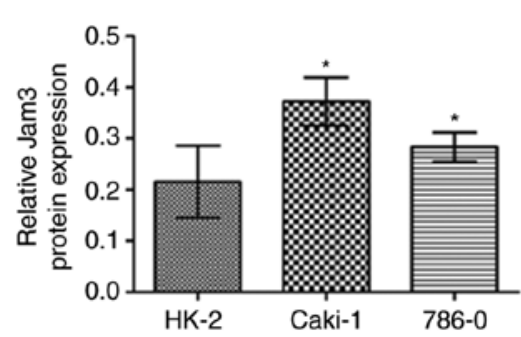

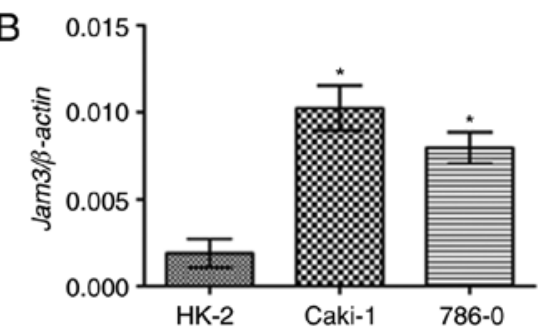

Figure 1. mRNA and protein expression of Jam3 in HK-2, Caki-1 and 786-0 cells. (A) Western blot analysis was performed to detect the protein level of Jam3, which showed that the protein expression of Jam3 in Caki-1 and 786-0 cells was increased compared with that in HK-2 cells ( $\mathrm{P}<0.05)$. (B) Reverse transcription-polymerase chain reaction analysis was performed to determine the mRNA expression levels of Jam3. Caki-1 and 786-0 cells were compared with HK-2 cells. $\beta$-actin was used as a loading control ( $\mathrm{P}<0.05)$. Jam3, junctional adhesion molecule 3; GAPDH, glyceraldehyde 3-phosphate dehydrogenase.

Cell migration assay. The Caki-1 and 786-0 cells were transfected with non-specific or Jam 3 siRNA for $24 \mathrm{~h}$, and the cells were digested, counted and suspended in serum-free DMEM. Following this, $100 \mu \mathrm{l}\left(2 \times 10^{5}\right.$ cells) were seeded in the upper chamber of a Transwell unit with an $8.0-\mu \mathrm{m}$ polycarbonate membrane (EMD Millipore) inserted in a 24 -well plate, and $500 \mu \mathrm{l}$ of culture medium with $10 \% \mathrm{FBS}$ was added to the lower chamber. The cells were cultured for $24 \mathrm{~h}$ at $37^{\circ} \mathrm{C}$, following which the cells on the top surface of the Transwell chamber were removed using a cotton swab. The cells adhering to the lower surface were fixed with $4 \%$ paraformaldehyde for $15 \mathrm{~min}$ and stained with crystal violet. The migration was assessed using an inverted phase contrast microscope in five randomly selected fields.

Statistical analysis. Data in the present study were analyzed using GraphPad Prism 5.0 software (GraphPad Software, Inc., La Jolla, CA, USA) and are presented as the mean \pm standard deviation. Statistical differences between multiple groups were compared using one-way analysis of variance followed by Tukey's post hoc test or Student's t-test (parametric)/Mann-Whitney (non-parametric) test. If an overall test was significant, Tukey's test was used for specific comparisons between individual groups. $\mathrm{P}<0.05$ was considered to indicate a statistically significant difference.

\section{Results}

$m R N A$ and protein levels of Jam3 in renal cancer cells. To assess the differential expression of Jam 3 in renal cancer cells and normal renal cells, the present study determined the mRNA and protein expression of Jam3 in the HK-2 human renal tubular epithelial cell line and the Caki- 1 and 786-0 renal cancer cell lines. It was found that the protein expression of Jam3 in Caki-1 and 786-0 cells was higher than that in HK-2 cells $(\mathrm{P}<0.05)$, as shown by the western blot analysis (Fig. 1A). The PCR results showed that the mRNA expression of Jam3 was also higher in the Caki-1 and 786-0 cells compared with that in the HK-2 cells $(\mathrm{P}<0.05$; Fig. 1B). These results suggested that the mRNA and protein levels of Jam3 were higher in renal carcinoma cells. Therefore, its effects were examined in subsequent experiments.

Jam3 degeneration induces apoptosis of renal carcinoma cells. To investigate the function of Jam 3 on the proliferation and apoptosis of Caki-1 and 786-0 cells, siRNAs were used. An siRNA targeting the Jam 3 mRNA sequence was transfected into Caki-1 and 786-0 cells, and the protein levels of Jam3 were assessed by western blot analysis. The results showed that Jam3 siRNA significantly silenced the protein expression of Jam3 $(\mathrm{P}<0.05)$, compared with that in the control group (Fig. 2A). The present study also examined whether Jam 3 affected the apoptosis of Caki-1 and 786- 0 cells using flow cytometry with FITC-Annexin V. The flow cytometry results showed that the percentage of apoptotic cells was higher in cells in which the Jam 3 gene was silenced (Fig. 2B).

Jam3 enhances the migratory ability of renal carcinoma cells. To further support a function of Jam 3 in renal cancer cell migration, Jam3 was exogenously knocked down in Caki-1 and 786- 0 cells using siRNA. The wound-healing assay revealed that, $24 \mathrm{~h}$ post-wounding, the wound width was larger in the Caki-1 and 786-0 cells in which the Jam 3 gene was silenced, compared with that in the non-specific siRNA group $(\mathrm{P}<0.05$; Fig. 3A and B). Notably, cell migration was measured via Transwell assays. Jam 3 siRNA knockdown significantly enhanced the migration of the Caki-1 and 786-0 cells. Fewer cells migrated in the Jam3 siRNA group ( $\mathrm{P}<0.05$; Fig. $3 \mathrm{C})$, compared with the non-specific siRNA group. These results suggested that Jam3 exhibited a marked effect on renal carcinoma cells, promoting the migration of Caki-1 and 786-0 cells and inhibiting Caki-1 and 786-0 cell migration when downregulated.

Effects of Jam3 on E-cadherin, N-cadherin, integrin $\beta 1$, MMP-2, Bcl-2 and Bax in renal carcinoma cells. E-cadherin and $\mathrm{N}$-cadherin are link proteins between cells and are important for the migration of cancer cells (18). Therefore, the present study measured the protein levels of E-cadherin and N-cadherin in Jam3 siRNA-transfected Caki-1 and 786-0 cells compared with the non-specific siRNA-transfected cells. It was found that the expression of E-cadherin was increased and the expression of $\mathrm{N}$-cadherin was decreased following transfection with Jam3 siRNA, compared with the negative siRNA (Fig. 4A). Integrin $\beta 1$ can induce cancer cell migration (19), and it was found that the protein level of integrin $\beta 1$ was also reduced in the Jam 3 siRNA group, compared with that in the control group ( $\mathrm{P}<0.05$; Fig. 4A). MMP-2 can degrade type IV collagen and contributes to cancer cell invasion (20). The knockdown of Jam3 in Caki-1 and 786-0 cells reduced the protein levels of MMP-2 (Fig. 4A). These data 
A

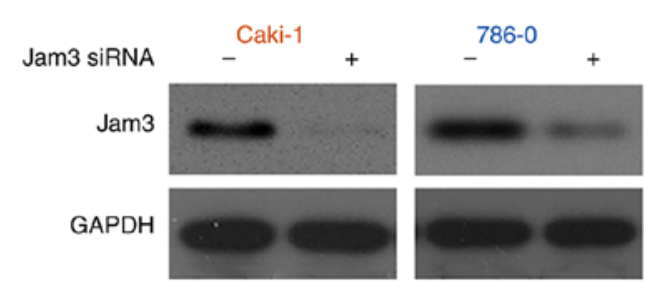

B

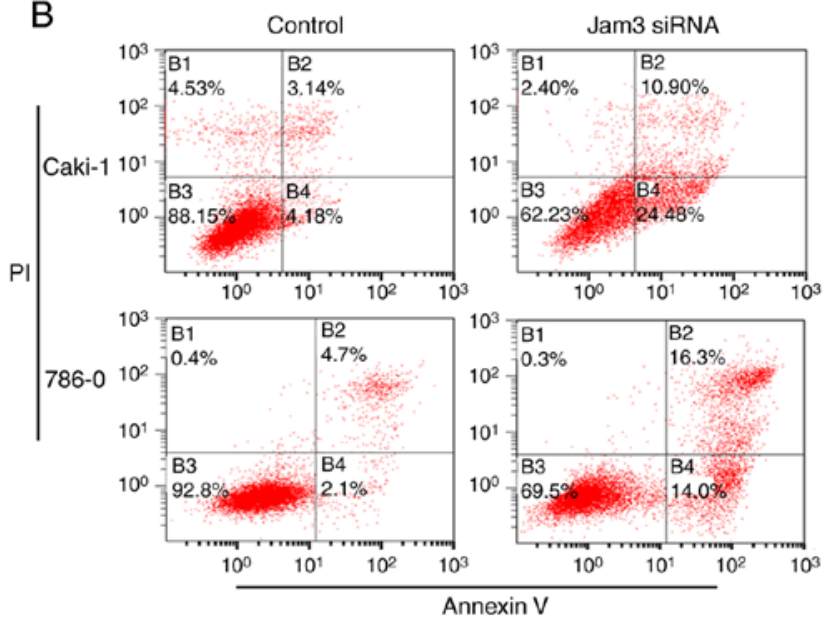

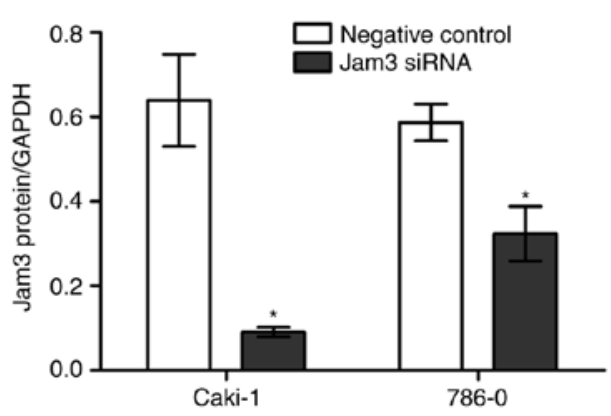
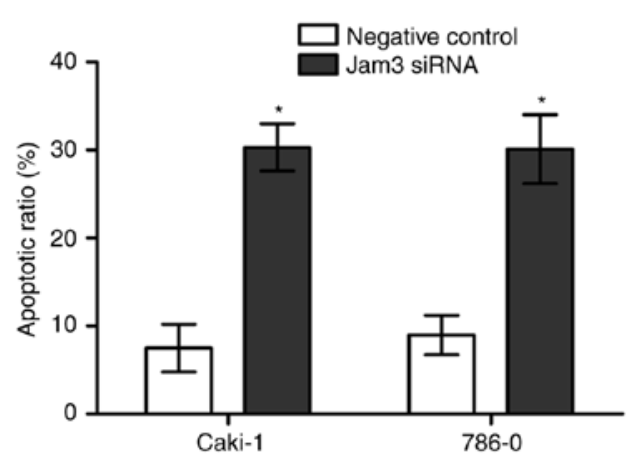

Figure 2. Increased apoptosis of Caki-1 and 786-0 cells transfected with Jam3 siRNA. (A) Cellular Jam3 protein was collected from Caki-1 and 786-0 cells transfected with non-specific siRNA or Jam 3 siRNA, and the protein levels of Jam 3 in each group were assessed by western blot analysis. GAPDH was used as a loading control ( $\left.{ }^{*} \mathrm{P}<0.05\right)$. (B) Effects of Jam3 knockdown on the apoptosis of Caki-1 and 786-0 cells were measured using flow cytometry ( $\mathrm{P}<0.05$ ). Jam3, junctional adhesion molecule 3; GAPDH, glyceraldehyde 3-phosphate dehydrogenase; siRNA, small interfering RNA; PI, propidium iodide.

indicated that Jam3 knockdown caused an increase in E-cadherin and Bax, and a decrease in N-cadherin, integrin $\beta 1$, MMP-2 and Bcl-2. All data for the Jam3 siRNA group were statistically significant when compared with the non-specific siRNA group $(\mathrm{P}<0.05$, Fig. 4B).

\section{Discussion}

As a common type of renal cancer, $\mathrm{RCC}$ has a high annual mortality rate (21-24). RCC accounts for $\sim 3 \%$ of adult malignant tumors and $85 \%$ of primary renal tumors. In China, renal cancer was expected to account for $1.5 \%$ of all new cancer cases in 2015, with a mortality rate of $\sim 35 \%$ (25). Therefore, the prognosis of RCC is poor $(21-23,26,27)$. Surgical resection of RCC is only suitable for a limited number of patients with early stage tumors $(21,28-30)$. Several studies $(13,31)$ have examined novel oncotargets for RCC. The present study identified Jam3 as an important gene in RCC, which has been reported as a junctional adhesion molecule. In the present study, the protein and mRNA levels of Jam3 were higher in renal carcinoma cells (Caki-1 and 786-0), compared with those in renal tubular epithelial cells $(\mathrm{HK}-2)$. It was reported previously that Jam 3 was overexpressed in gastric adenocarcinoma tumors and was involved with the progression of gastric tumor cells (32). Junctional adhesion molecule-C (JAM-C) is a tight junction-associated transmembrane protein expressed on mammalian endothelial cells. It is involved in leukocyte diapedesis and interacts with the leukocyte integrin M2 (14). Jam 3 is involved in leukocyte transendothelial migration and can form homophilic (JAM-C/JAM-C) and heterophilic interactions with the leukocyte integrin $\alpha_{M} \beta_{2}$. In a previous study, the effect of early administration of monoclonal antibodies directed against JAM-C in cerulein-induced acute pancreatitis was assessed (33). It was suggested that Jam 3 expressed by endothelial cells contributes to the pathophysiology of acute pancreatitis and may be considered a target for clinical applications (33). The methylation status of Jam3 has been used as a biomarker for the diagnosis of preneoplastic and neoplastic lesions of the cervix (10). The present study found that renal carcinoma cell apoptosis was enhanced following transfection with Jam3 siRNA. Therefore, it was hypothesized that Jam3 inhibits renal carcinoma cell apoptosis. Previous results have shown that the expression of Jam3 can be regulated during B-cell maturation. Furthermore, the expression of JAM-C has been used to divide $\mathrm{CD} 27^{+} \mathrm{B}$ cells into two subtypes: JAM-C ${ }^{+}$ cells, as the major proportion of circulating $\mathrm{CD} 27^{+}$cells in the peripheral blood, and JAM-C ${ }^{-}$cells, identified as a phenotype of germinal center $\mathrm{B}$ cells of secondary lymphoid organs. JAM-C- cells exhibit high expression of BCL6, a nuclear proto-oncogene with a pivotal role in germinal center formation (33), whereas JAM-C ${ }^{+}$cells express a low level of BCL6, which is a signature of extrafollicular cells (34).

According to the data obtained in the present study, Jam3 knockdown in Caki-1 and 786-0 cells inhibited cancer cell migration and the protein expression of $\mathrm{N}$-cadherin, and increased the expression of E-cadherin. The PDZ domain-binding motif located in the cytoplasmic tail of JAMs mediates interactions with intracellular scaffolding proteins, including zonula occludens 1 , thereby providing a link to the cytoskeleton (35). Integrin $\beta 1$ is considered to be important in cell migration by redistributing integrins from the retracting edges to the migrating front (36). Li et al and Dai et al previously 
A

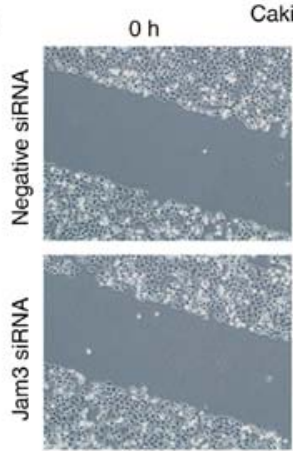

B

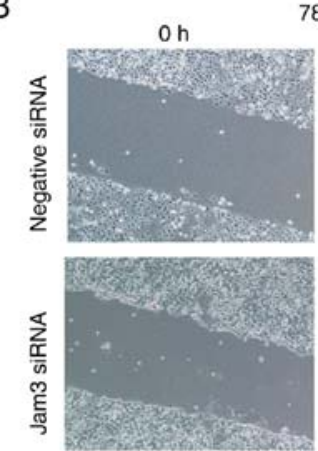

C

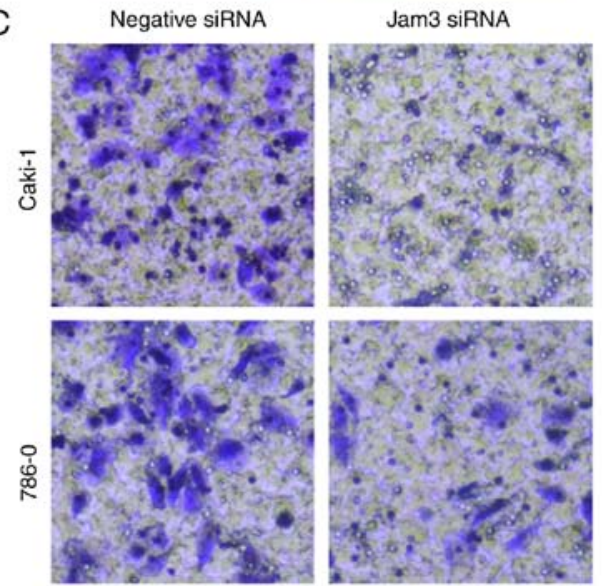

$24 \mathrm{~h}$

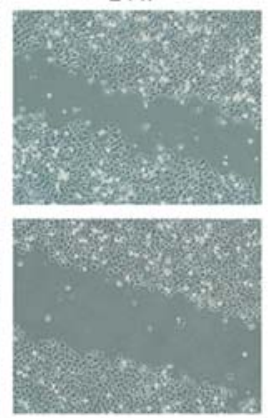

$786-0 \quad 24 \mathrm{~h}$
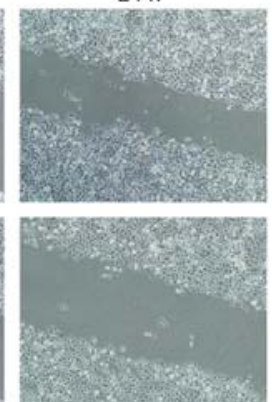

Jam3 siRNA

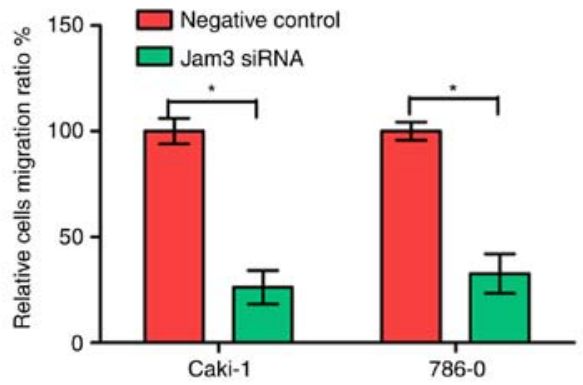

Figure 3. Jam3 mediates the migration of Caki-1 and 786-0 cells. (A) Wound sites/interval between the two wound sites of Caki-1 cells) were detected and images were captured. Images show the repair of the wound in the two groups ( $\mathrm{P}<0.05$ ). (B) Wound sites/interval between the two wound sites of 786-0 cells were measured and images were captured. Images show the repair of the wound in the two groups ( $\left.{ }^{*} \mathrm{P}<0.05\right)$. (C) Migration of Caki-1 and 786-0 cells was measured using a Transwell chamber ( $\mathrm{P}<0.05)$. Original magnification of all images, $\mathrm{x} 200$. Jam3, junctional adhesion molecule 3; siRNA, small interfering RNA.
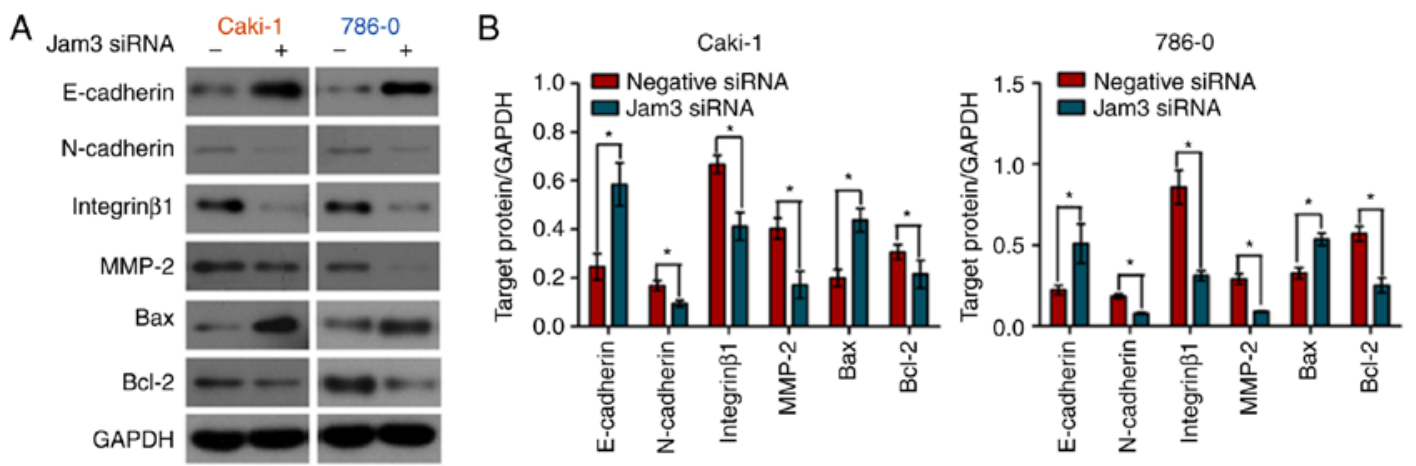

Figure 4. Differential expression of E-cadherin, N-cadherin, integrin $\beta 1$ and MMP-2 in Caki-1 and 786-0 cells transfected with non-specific siRNA and Jam3 siRNA. (A) Cellular protein was collected from Caki-1 and 786-0 cells transfected with non-specific siRNA or Jam3 siRNA. Western blot analysis was performed to assess the levels of E-cadherin, N-cadherin, integrin 31 , MMP-2, Bax and Bcl-2. GAPDH was used as a loading control. (B) Average grey values represented as a histogram ("P<0.05). Jam3, junctional adhesion molecule 3; MMP-2, matrix metalloproteinase 2; Bcl-2, B-cell lymphoma 2; Bax, Bcl-2-associated X protein; GAPDH, glyceraldehyde 3-phosphate dehydrogenase; siRNA, small interfering RNA. 
demonstrated that endocytic integrin $\beta 1$ accumulated at the recycling endosome under starvation conditions, and was recycled following acute stimulation $(37,38)$. In human aortic smooth muscle cells, KP-10 significantly suppressed angiotensin II-induced migration and proliferation, but increased apoptosis and the activities of MMP-2 and MMP-9 via the upregulation of extracellular signal-regulated kinase 1 and 2 , p38, Bax, and caspase-3. MMP-2 increases cancer cell migration by degrading extracellular collagen tissue (39).

In conclusion, the present study showed that Jam3 was expressed at a high level in renal carcinoma cells. The downregulation of Jam3 significantly enhanced apoptosis and suppressed migration of renal carcinoma cells. It is known that the link proteins E-cadherin and $\mathrm{N}$-cadherin, and integrin $\beta 1$ and MMP-2 are associated with tumor migration ability. According to the present study, transfection of Jam3 siRNA in renal carcinoma cells promoted the protein level of E-cadherin, and downregulated the protein levels of N-cadherin, integrin $\beta 1$ and MMP-2. Therefore, Jam3 may affect renal carcinoma cell migration and apoptosis by regulating E-cadherin, $\mathrm{N}$-cadherin, integrin $\beta 1$ and MMP-2. However, whether Jam 3 is also expressed at a high level in clinical samples remains to be elucidated. The present study did not examine in vivo Jam 3 levels in patients with RCC; however, this question is to be addressed in future investigations. Jam 3 may be a potential target for clinical applications, therefore, it is would be useful to examine this novel RCC medicine in future investigations.

\section{Acknowledgements}

Not applicable.

\section{Funding}

This study was supported by the National Nature Science Foundation of China (grant no. 81200528) and Prevention and Control Strategies for Major Diseases, Diagnosis and Treatment Practices, and Evaluation of Effects (grant no. 2015BAI12B05; Type: 12th five-year public relations).

\section{Availability of data and materials}

All data generated or analyzed during this study are included in this published article.

\section{Authors' contributions}

$\mathrm{XL}$ and JS conceived the study; AY and WZ performed the experiments; FZ, JiaL and JingL analyzed the data; JS wrote the manuscript. All authors have read and approved the final version of the manuscript.

\section{Ethics approval and consent to participate}

Not applicable.

\section{Patient consent for publication}

Not applicable.

\section{Competing interests}

The authors declare that they have no competing interests.

\section{References}

1. Hirbod-Mobarakeh A, Gordan HA, Zahiri Z, Mirshahvalad M, Hosseinverdi S, Rini BI and Rezaei N: Specific immunotherapy in renal cancer: A systematic review. Ther Adv Urol 9: 45-58, 2017.

2. Turajlic S, Larkin J and Swanton C: SnapShot: Renal cell carcinoma. Cell 163: 1556-1556.e1, 2015.

3. Ling S, Nheu L and Komesaroff PA: Cell adhesion molecules as pharmaceutical target in atherosclerosis. Mini Rev Med Chem 12: 175-183, 2012.

4. Mazza C, Escudier B and Albiges L: Nivolumab in renal cell carcinoma: Latest evidence and clinical potential. Ther Adv Med Oncol 9: 171-181, 2017.

5. Thakor P, Song W, Subramanian RB, Thakkar VR, Vesey DA and Gobe GC: Maslinic acid inhibits proliferation of renal cell carcinoma cell lines and suppresses angiogenesis of endothelial cells. J Kidney Cancer VHL 4: 16-24, 2017.

6. Heng DY: The next 10 years: Challenges for the future and overcoming resistance to targeted therapies for renal cell carcinoma. Can Urol Assoc J 10 (11-12 Suppl 7): S256-S258, 2016.

7. Lim SH, Hwang IG, Ji JH, Oh SY, Yi JH, Lim DH, Lim HY, Lee SJ and Park SH: Intrinsic resistance to sunitinib in patients with metastatic renal cell carcinoma. Asia Pac J Clin Oncol 13: 61-67, 2017.

8. Santoso S, Sachs UJ, Kroll H, Linder M, Ruf A, Preissner KT and Chavakis T: The junctional adhesion molecule 3 (JAM-3) on human platelets is a counterreceptor for the leukocyte integrin Mac-1. J Exp Med 196: 679-691, 2002.

9. Galkina E and Ley K: Vascular adhesion molecules inatherosclerosis. Arterioscler Thromb Vasc Biol 27: 2292-2301, 2007.

10. Yin A, Zhang Q, Kong X, Jia L, Yang Z, Meng L, Li L, Wang X, Qiao Y, Lu N, et al: JAM3 methylation status as a biomarker for diagnosis of preneoplastic and neoplastic lesions of the cervix. Oncotarget 6: 44373-44387, 2015.

11. Gurzu S, Silveanu C, Fetyko A, Butiurca V, Kovacs Z and Jung I: Systematic review of the old and new concepts in the epithelial-mesenchymal transition of colorectal cancer. World J Gastroenterolog 22: 6764-6775, 2016.

12. Song Y, Wang L, Yang F, Wu X, Duan Q and Gong Z: Increased expressions of integrin subunit $\beta 1, \beta 2$ and $\beta 3$ in patients with acute infection. Int J Med Sci 12: 639-643, 2015.

13. Zheng B, Zhu H, Gu D, Pan X, Qian L, Xue B, Yang D, Zhou J and Shan Y: MiRNA-30a-mediated autophagy inhibition sensitizes renal cell carcinoma cells to sorafenib. Biochem Biophys Res Commun 459: 234-239, 2015.

14. Zheng B, Mao JH, Qian L, Zhu H, Gu DH, Pan XD, Yi F and Ji DM: Pre-clinical evaluation of AZD-2014, a novelmTORC1/2 dual inhibitor, against renal cell carcinoma. Cancer Lett 357: 468-475, 2015.

15. Zheng B, Mao JH, Li XQ, Qian L, Zhu H, Gu DH and Pan XD: Over-expression of DNA-PKcs in renal cell carcinomaregulates mTORC2 activation, HIF-2alpha expression and cell proliferation. Sci Rep 6: 29415, 2016.

16. Wu D, Ding J, Wang L, Pan H, Zhou Z, Zhou J and Qu P: microRNA-125b inhibits cell migration and invasion bytargeting matrix metallopeptidase 13 in bladder cancer. Oncol Lett 5: 829-834, 2013.

17. Livak KJ and Schmittgen TD: Analysis of relative gene expression data using real-time quantitative PCR and the $2^{-\Delta \Delta C \mathrm{~T}}$ method. Methods 25: 402-408, 2001.

18. Mook OR, Frederiks WM and Van Noorden CJ: The role of gelatinases in colorectal cancer progression and metastasis. Biochim Biophysica Acta 1705: 69-89, 2004.

19. Su NW, Wu SH, Chi CW, Liu CJ, Tsai TH and Chen YJ: Metronomic cordycepin therapy prolongs survival of oral cancer-bearing mice and inhibits epithelial-mesenchymal transition. Molecules 22: E629, 2017.

20. Matsubara M and Bissell MJ: Inhibitors of Rho kinase (ROCK) signaling revert the malignant phenotype of breast cancer cells in 3D context. Oncotarge 7: 31602-31622, 2016.

21. Moroz A, Delella FK, Lacorte LM, Deffune E and Felisbino SL: Fibronectin induces MMP2 expression in human prostate cancer cells. Biochem Biophys Res Commun 430: 1319-1321, 2013. 
22. Motzer RJ, Hutson TE, Cella D, Reeves J, Hawkins R, Guo J, Nathan P, Staehler M, de Souza P, Merchan JR, et al: Pazopanib versus sunitinibin metastatic renal-cell carcinoma. N Engl J Med 369: 722-731, 2013.

23. Cohen HT and McGovern FJ: Renal-cell carcinoma. N Engl J Med 353: 2477-2490, 2005

24. Motzer RJ, Bander NH and Nanus DM: Renal-cell carcinoma. N Engl J Med 335: 865-875, 1996

25. Siegel R, Ma J, Zou Z and Jemal A: Cancer statistics, 2014. CA Cancer J Clin 64: 9-29, 2014.

26. Chen W, Zheng R, Baade PD, Zhang S, Zeng H, Bray F, Jemal A, Yu XQ and He J: Cancer statistics in China, 2015. CA Cancer J Clin 66: 115-132, 2016.

27. Fiori E, De Cesare A, Galati G, Bononi M, D'Andrea N, Barbarosos A, Izzo L and Bolognese A: Prognostic significanceof primary-tumor extension, stage and grade of nucleardifferentiation in patients with renal cell carcinoma. J Exp Clin Cancer Res 21: 229-232, 2002.

28. Uygur MC, Usubütün A, Ozen H, Ayhan A and Kendi S: Prognosticfactors and the role of nephrectomy in metastatic renal cellcarcinoma. J Exp Clin Cancer Res 18: 397-401, 1999.

29. Amato RJ: Chemotherapy for renal cell carcinoma. Semin Oncol 27: 177-186, 2000.

30. Ljungberg B, Cowan NC, Hanbury DC, Hora M, Kuczyk MA, Merseburger AS, Patard JJ, Mulders PF and Sinescu IC; European Association of Urology Guideline Group: EAU guidelines on renal cell carcinoma: The 2010 update. Eur Urol 58: 398-406, 2010.

31. Dutcher JP and Nanus D: Long-term survival of patients with sarcomatoid renal cell cancer treated with chemotherapy. Med Oncol 28: 1530-1533, 2011.

32. Hajjari M, Behmanesh M, Sadeghizadeh M and Zeinoddini M: Junctional adhesion molecules 2 and 3 may potentially be involved in progression of gastric adenocarcinoma tumors. Med Oncol 30: 380, 2013.
33. Vonlaufen A, Aurrand-Lions M, Pastor CM, Lamagna C, Hadengue A, Imhof BA and Frossard JL: The role of junctional adhesion molecule C (JAM-C) in acute pancreatitis. J Pathol 209: 540-548, 2006

34. Phan RT and Dalla-Favera R: The BCL6 proto-oncogene suppresses p53 expression in germinal-centre B cells. Nature 432: 635-639, 2004.

35. Ebnet K, Aurrand-Lions M, Kuhn A, Kiefer F, Butz S, Zander K, Meyer zu Brickwedde MK, Suzuki A, Imhof BA and Vestweber D: The junctional adhesion molecule (JAM) family members JAM-2 and JAM-3 associate with the cell polarity protein PAR-3: A possible role for JAMs in endothelial cell polarity. J Cell Sci 116: 3879-3891, 2003.

36. Ebnet K, Suzuki A, Ohno S and Vestweber D: Junctional adhesion molecules (JAMs): More molecules with dual functions. J Cell Sci 117: 19-29, 2004.

37. Li J, Ballif BA, Powelka AM, Dai J, Gygi SP and Hsu VW: Phosphorylation of ACAP1 by Akt regulates the stimulation-dependent recycling of integrin beta1 to control cell migration. Dev Cell 9: 663-673, 2005.

38. Dai J, Li J, Bos E, Porcionatto M, Premont RT, Bourgoin S, Peters PJ and Hsu VW: ACAP1 promotes endocytic recycling by recognizing recycling sorting signals. Dev Cell 7: 771-776, 2004.

39. Sato K, Shirai R, Hontani M, Shinooka R, Hasegawa A, Kichise T, Yamashita T, Yoshizawa H, Watanabe R, Matsuyama TA, et al: Potent vasoconstrictor kisspeptin-10 induces atherosclerotic plaque progression and instability: Reversal by its receptor GPR54 antagonist. J Am Heart Assoc 6: e005790, 2017. 